\title{
Malignant Smooth Muscle Neoplasm
}

National Cancer Institute

\section{Source}

National Cancer Institute. Malignant Smooth Muscle Neoplasm. NCI Thesaurus. Code C6511.

A malignant neoplasm arising from smooth muscle. 